\title{
All in this together: deservingness of government aid during the COVID-19 pandemic
}

\author{
Aengus Bridgman \\ PhD Candidate, McGill University \\ aengus.bridgman@mail.mcgill.ca \\ 438-889-5682 \\ (a)AengusBridgman \\ Peter John Loewen \\ Professor, University of Toronto \\ peter.loewen@utoronto.ca \\ (a)PeejLoewen \\ Eric Merkley \\ Postdoctoral Fellow, University of Toronto \\ eric.merkley@utoronto.ca \\ @EricMerkley \\ Taylor Owen \\ Associate Professor, McGill University \\ taylor.owen@mcgill.ca \\ @taylor_owen \\ Derek Ruths \\ Associate Professor, McGill University \\ derek.ruths@mcgill.ca \\ @derekruths
}

May 29, 2020

Word count: 1987 


\begin{abstract}
The COVID-19 pandemic has placed unprecedented pressure on governments to engage in widespread cash transfers directly to citizens to help mitigate economic losses. These programs are major redistribution efforts aimed at a variety of sub-groups within society (the unemployed, those with children, those with pre-existing health conditions, etc.) and there has been remarkably little resistance to these government outlays. We employ a novel and pre-registered paired vignette experiment to assess support for government aid during the pandemic in a large, nationally representative sample. We evaluate whether the "normal" deservingness hierarchy and considerations of social affinity or material self-interest continue to drive preferences of Canadians regarding redistribution. We find only small deservingness considerations and little evidence that redistribution preferences are informed by similarity considerations. Instead, we find broad, generous, and non-discriminatory support for direct cash transfers during this period of crisis.
\end{abstract}


The COVID-19 pandemic has been met with unparalleled government fiscal action and mass public mobilization and coordination. While citizens are engaging in a massive social coordination effort to stop the spread of the coronavirus, governments around the world have engaged in large-scale stimulus spending that far outstrips that spent during, and in the aftermath of, the 2008 financial crisis. A major portion of this spending has been in the form of cash transfers directly to citizens. These spending measures have been implemented at great cost and with a much-needed urgency. And yet, we have limited knowledge of the types of financial transfers supported by the population. Critical to developing this understanding is research into perceptions of deservingness which underline social welfare policy preferences and political decisions (Petersen 2012).

\section{Deservingness in times of crisis}

Previous research has shown the importance of the deservingness heuristic for complex policy decisions; support for redistributive policies has been observed to be higher when those policies are targeted at populations who are perceived as victims of uncontrollable events (Skitka and Tetlock 1993). The pandemic is one such uncontrollable event, and governments around the world have faced little criticism for unprecedented, large-scale individual transfers, even those targeted at specific populations which may have been perceived as less deserving in the past. This may indicate an important response to a crisis wherein common deservingness heuristics are less adhered to in favour of more generosity and inclusivity. Existing research does not strongly point towards such a phenomenon, with previous research on economic crises yielding mixed results. Some have found that crises such as the Great Recession do not shift attitudes towards redistribution in the aggregate (Brooks and Manza 2013; Soroka and Wlezien 2014), while 
others find that there is some increased support amongst middle- and high-income earners (Rosset and Pontusson 2014).

During normal times, work elsewhere has shown the deservingness heuristic is sensitive to prejudicial attitudes, such as those on ethnicity and race (DeSante 2013; Harell, Soroka, and Iyengar 2016). Citizenship and immigration are also important factors, with a body of evidence showing that immigrants are generally perceived as the least deserving group for social spending (Ford 2016). Deservingness has also been examined in relation to family commitments; those with young children are perceived as more deserving of aid relative to their peers without children (Will 1993). Finally, health costs and unemployment benefits are also important deservingness considerations. Jensen and Petersen (2017) find that those who are sick or require healthcare are typically deemed as most deserving. Meanwhile, evaluations of deservingness of the unemployed can vary based on context, but those who are unemployed through no fault of their own are typically perceived as more deserving (van Oorschot 2006).

In addition to this hierarchy there are well documented so-called similarity preferences, where support for redistributive policies is higher when the beneficiaries of the redistribution are perceived as similar. Two conceptually distinct motivations are critical to understanding these similarity preferences: social affinity and material self-interest. Social affinity studies find that people care more about the well-being of others with whom they share certain characteristics (Kristov, Lindert, and McClelland 1992); thus demonstrating that generosity is conditional on the ability to empathize with the potential recipient. Furthermore, the literature on material selfinterest indicates that decisions around deservingness can be influenced by a desire to capture government resources for one's own group, community, or other sets of interests (Campbell et al. 
1960). Differentiating between the two mechanisms is challenging. Nonetheless, objective indicators of similarity have been shown to powerfully predict redistributive attitudes (Chong, Citrin, and Conley 2001).

However, individuals do not only maximize material self-interest or focus on social affinity. They may factor in considerations of social solidarity (Cavaillé and Trump 2015; Fong 2001). The deservingness hierarchy and motivations of material self-interest may be overridden by collective considerations during a pandemic when concerns about national wellbeing are primed (Olivera Angulo 2014). Here we ask two questions focused on support for government aid during a crisis: 1) do individuals continue to adhere to the status quo hierarchy of deservingness? And 2) do individuals continue to be influenced by similarity considerations?

\section{Data and Method}

To probe these dynamics, we conducted a survey of 2,522 Canadian citizens 18 years and older from the online panel provider Dynata. The survey was fielded from May 21-27, 2020. National level quotas were set on region (i.e. Atlantic, Quebec, Ontario, and West), age, gender, and language. Respondents were weighted within each region of Canada by gender and age based on data from the 2016 Canadian census.

We employ a paired factorial vignette; see a preregistration of this design and associated hypotheses here https://osf.io/2rqwm?view_only=2023b195642140669975c21816be035a. Each respondent was presented with two pairs of profiles of hypothetical Canadian residents. These profiles consisted of seven randomized features: 1) name (including clear ethnicity/gender indicators); 2) citizenship; 3) health status; 4) marital status; 5) children; 6) employment status; 7) and income before the pandemic. This results in 10,088 assessed profiles with 3,072 possible 
permutations, each of which was equally likely with no constrained permutations. Following each pair of profiles, respondents were asked the following for each profile: "How much money should $<$ name $>$ receive from the government during the pandemic per month?", and were given a slider to report their answer from $\$ 0-4000$ (slider resting point was at $\$ 0$ ). Details on the exact instrument can be found in the supplementary materials; similar instruments have been deployed in other research examining deservingness of government allocations (e.g. Harell, Soroka, and Iyengar 2016; Will 1993).

Our pre-registration aligns with the theory above. We anticipate that allocation of government benefits would follow a deservingness hierarchy generally developed in the extant literature. We expect whites, citizens, those with young children, those with pre-existing health issues, those who lost income and employment due to the pandemic, and those with lower pre-pandemic incomes to be perceived as the most deserving.

Moreover, we anticipate that material self-interest and social affinity would shape respondents' redistribution preferences. First, we expect the effects of income or job loss due to the pandemic on deservingness to be stronger among those whose job is at risk from the pandemic, or among those who have already been laid off. Second, we anticipate the effect of children on deservingness to be stronger for those with children. We interact this variable with a dichotomized version of the corresponding feature where 1 indicates the profile has children of any age. Third, we anticipate the effect of pre-existing health conditions on deservingness to be stronger if they, or someone in their household, has had a recent illness. Finally, we expect the negative effect of pre-pandemic income on deservingness to be stronger among low income respondents, and potentially reverse direction for high income respondents. Details on our 
similarity variables can be found in the supplemental appendix. Note that our experimental design does not allow us to distinguish social affinity from material self-interest motivation.

\section{Results}

Panel A of Figure 1 provides the marginal means that test our unconditional expectations. The average marginal component effects (AMCEs) are found in Panel B. The grand mean of the suggested allocation across all assessed profiles is $\$ 1592$, indicating respondents were inclined to support a substantial amount of government assistance during the pandemic. Contrary to our preregistered expectations, there were no significant differences between allocation for whites (\$1577) and non-whites (\$1597).
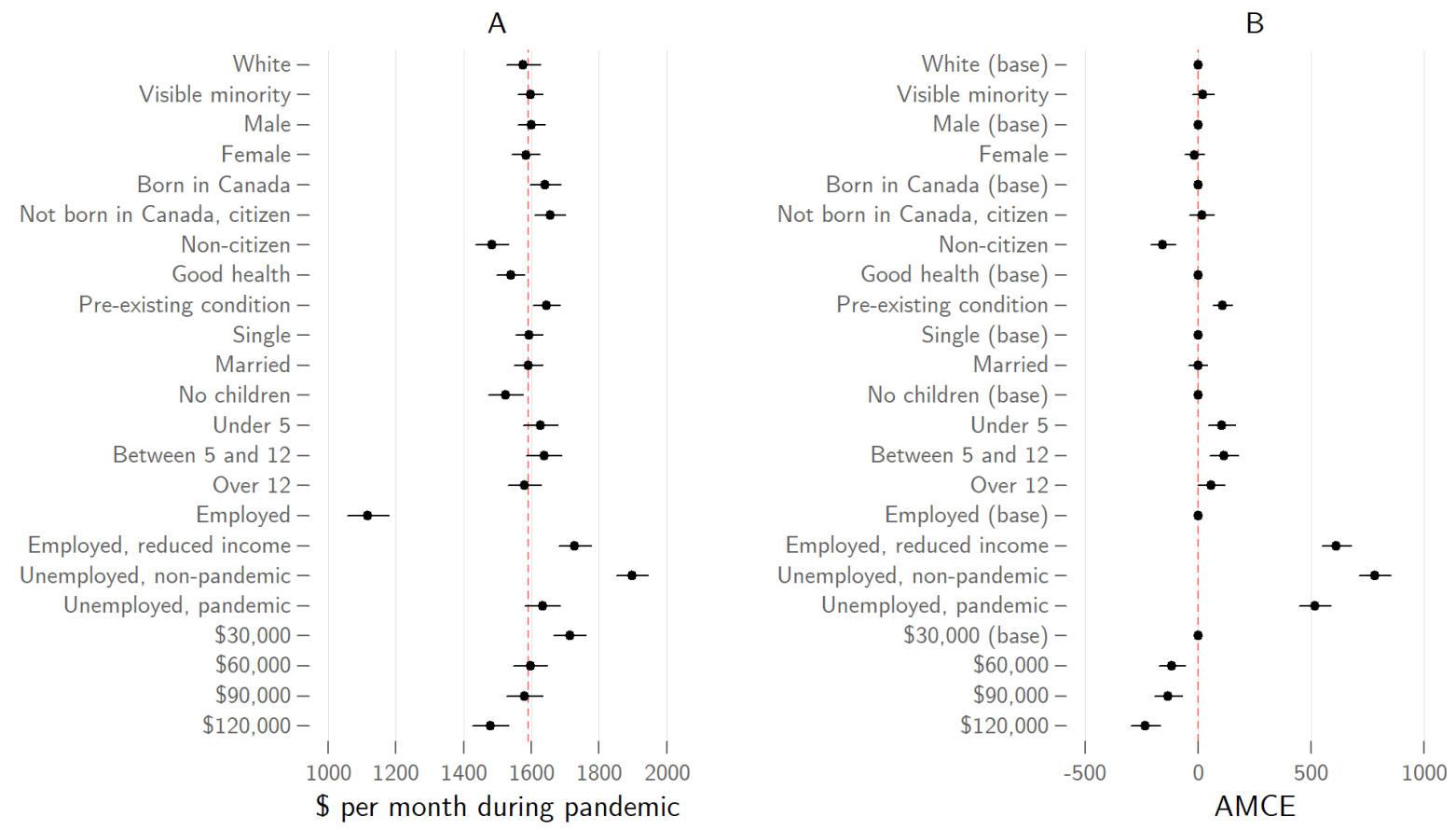

Figure 1. Marginal means (A); AMCEs (B). Note: Bonferroni corrected 95\% confidence intervals; dashed line in panel $\mathrm{A}$ is the grand mean.

Most of our other expectations were met to some degree, though we did not anticipate finding effect sizes this small. Non-citizens were allocated significantly less assistance $(\$ 1484)$ than 
citizens, but there was no difference between those who were $(\$ 1641)$ or were not born in Canada (\$1656). People with children were allocated more support than people with no children (\$1524), though this was true only for those with children under 5 (\$1626) and between 5 and 12 (\$1637), but not for those with children over 12 (\$1581). People with pre-existing conditions were allocated more $(\$ 1645)$ than those without $(\$ 1539)$. Pre-pandemic income was also negatively associated with deservingness. People earning $\$ 30,000$ prior to the crisis were allocated more (\$1714) than those earning $\$ 60,000$ (\$1597), $\$ 90,000$ (\$1580), and $\$ 120,000$ $(\$ 1479)$.

By far the largest effect we find is attributed to employment status. As expected, people who are employed and unaffected by the pandemic were allocated, on average, far less (\$1117) than those who lost income $(\$ 1728)$ or employment $(\$ 1632)$. Contrary to expectations, those who were unemployed for reasons unrelated to the pandemic were allocated the most $(\$ 1898)$.

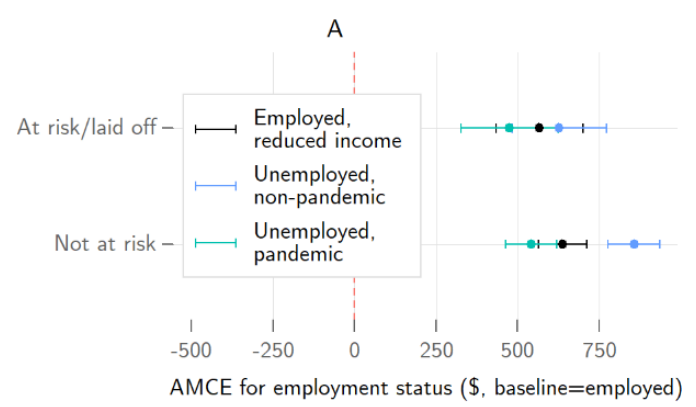

C

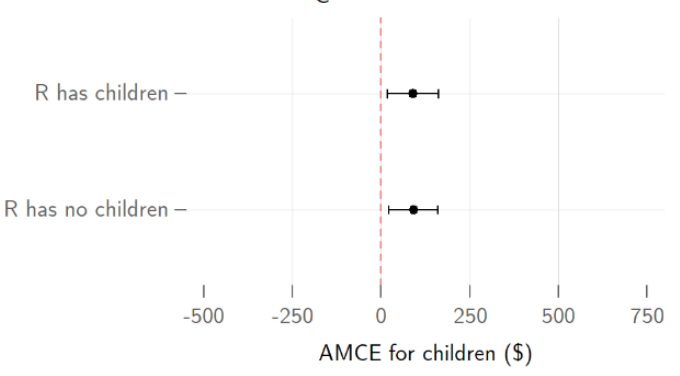

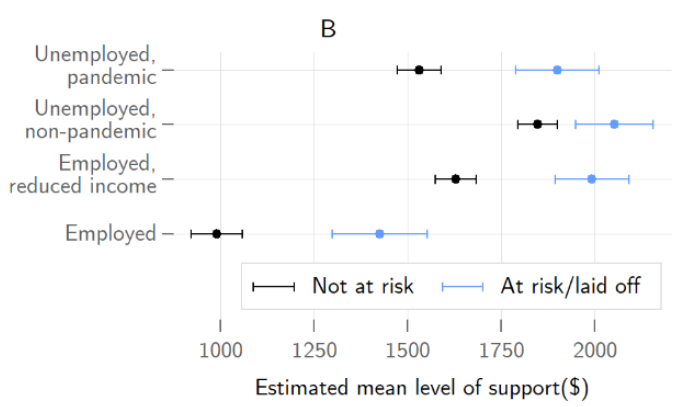

D

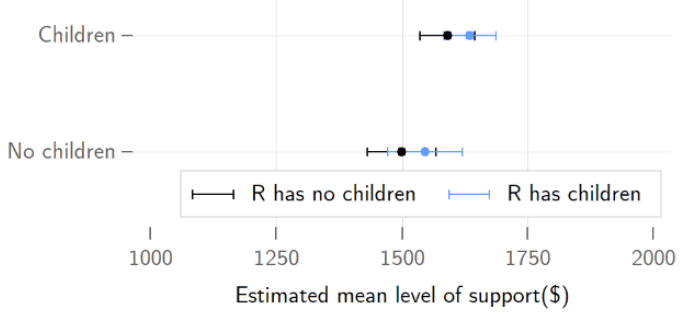

Figure 2. Sub-group AMCEs for employment status (A), children (C); sub-group marginal means for employment status (B), children (D). Note: $95 \%$ confidence intervals. 
Figure 2 presents the results of our similarity-based tests for employment status and children using sub-group AMCEs since our hypotheses are about sub-group differences in causal effects. We also provide side-by-side comparisons with the sub-group marginal means in this figure because the interpretation of AMCEs can be sensitive to the choice of reference category (Leeper, Hobolt, and Tilley 2020). We find little evidence that there are any social affinity or material self-interest dynamics driving allocations. The effects of income and employment loss on deservingness are similar for those whose employment is at risk (or were laid off) and those whose employment is not in jeopardy, contrary to expectations (Figure 2A). The only significant difference is that there was relatively more support for those with unemployment unrelated to the pandemic among those not at risk of unemployment, which we had not anticipated.

A

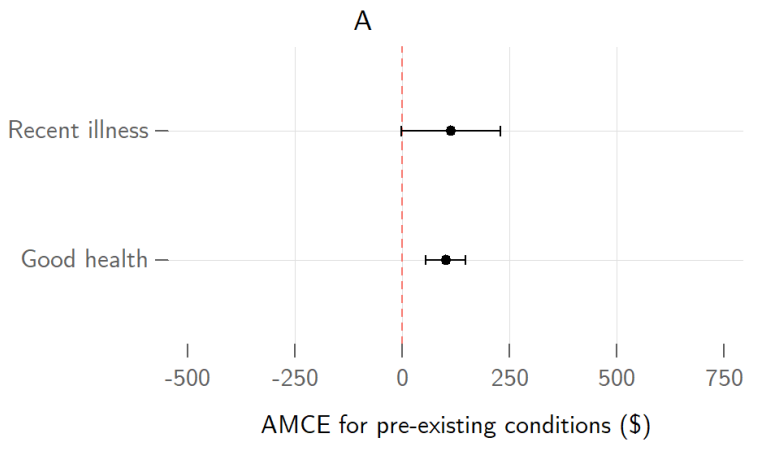

C

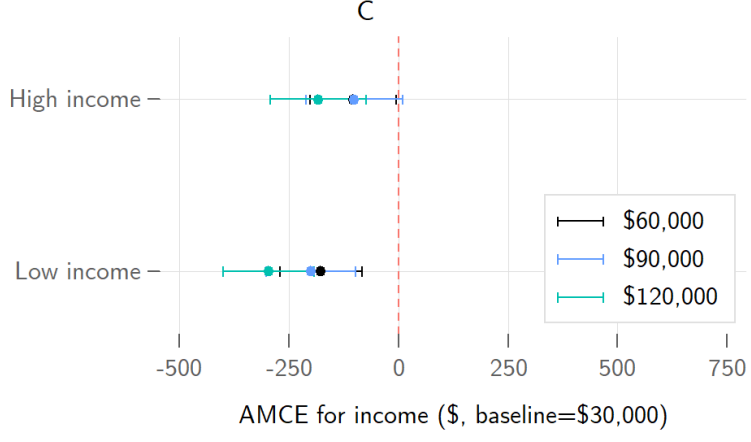

B

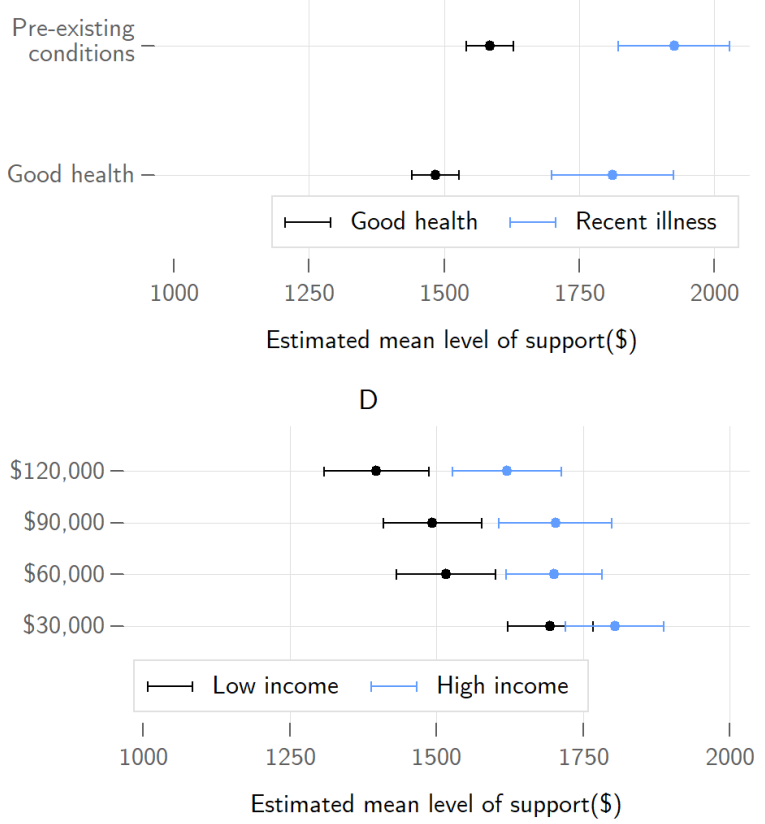

Figure 3. Sub-group AMCEs for health status (A), income (C); sub-group marginal means for health status (B), income (D). Note: 95\% confidence intervals. 
Figure 3 shows the same estimates, but for our tests related to health status and pre-pandemic income. The effect of pre-existing health conditions is similar for those in good health and those who have experienced recent illness (Figure 3A). This latter group, however, is more generous on average (Figure 3B). There is some indication that respondent income influences distributional preferences. Figure 3D shows that low income respondents appear to be more sensitive in their deservingness evaluations to income, comparatively awarding more aid to low income profiles even while they are less generous than high income respondents across all categories. However, the sub-group AMCEs are not significantly different (Figure 3C). Finally, we ran similarity tests for gender and marital status and find further null results, as shown in the supplementary appendix.

\section{Discussion}

Canadian governments have provided unprecedented support to individuals who have lost income, those with young children, those at greater risk of severe health complications arising from the crisis, students, and a variety of other groups. Canadians are strongly supportive of these dramatic and wide-reaching cash transfers at levels that compare to those which the government is currently distributing. Critically, we find that ethnic and immigration-based considerations do not strongly drive deservingness (although there is a penalty for non-citizens) and instead where allocations differ, they do so in practical matters such as pre-crisis income, children in the household and their ages, income loss, and risk for health complications. Furthermore, Canadians are not allocating support based on their own social affinity or material self-interest. Those who have been more affected by the crisis (whether through job loss, low 
pre-crisis income, or illness) do generally support larger transfers, but this largess extends to all potential recipients and not only to those like them.

The COVID-19 pandemic is causing near universal economic and social dislocation. During this period, support for government aid is high, unencumbered by typical considerations such as deservingness or similarity. These findings provide nuance to existing literature on how attitudes towards redistribution are informed by prejudice or ethnocentrism, as well as social affinity or material self-interest. During times of crisis, people are primed with concerns about national wellbeing, redistributive preferences evidence a powerful collective sentiment that citizens are "all in this together." 


\section{References}

Brooks, Clem, and Jeff Manza. 2013. “A Broken Public? Americans’ Responses to the Great Recession." American Sociological Review 78(5): 727-48.

Campbell, Angus, Philip E Converse, Warren E Miller, and Donald E Stokes. 1960. The American Voter. Chicago, IL: University of Chicago Press.

Cavaillé, Charlotte, and Kris-Stella Trump. 2015. "The Two Facets of Social Policy Preferences." The Journal of Politics 77(1): 146-60.

Chong, Dennis, Jack Citrin, and Patricia Conley. 2001. "When Self-Interest Matters." Political Psychology 22(3): 541-70.

DeSante, Christopher D. 2013. "Working Twice as Hard to Get Half as Far: Race, Work Ethic, and America's Deserving Poor." American Journal of Political Science 57(2): 342-56.

Fong, Christina. 2001. "Social Preferences, Self-Interest, and the Demand for Redistribution." Journal of Public Economics 82(2): 225-46.

Ford, Robert. 2016. "Who Should We Help? An Experimental Test of Discrimination in the British Welfare State." Political Studies 64(3): 630-50.

Harell, Allison, Stuart Soroka, and Shanto Iyengar. 2016. "Race, Prejudice and Attitudes toward Redistribution: A Comparative Experimental Approach.” European Journal of Political Research 55(4): 723-44.

Jensen, Carsten, and Michael Bang Petersen. 2017. "The Deservingness Heuristic and the Politics of Health Care." American Journal of Political Science 61(1): 68-83.

Kristov, Lorenzo, Peter Lindert, and Robert McClelland. 1992. "Pressure Groups and Redistribution." Journal of Public Economics 48(2): 135-63.

Leeper, Thomas J., Sara B. Hobolt, and James Tilley. 2020. "Measuring Subgroup Preferences in Conjoint Experiments." Political Analysis 28(2): 207-21.

Olivera Angulo, Javier. 2014. "Preferences for Redistribution after the Economic Crisis." Economics and Business Letters 3(3). https://orbilu.uni.lu/handle/10993/16926 (May 27, 2020).

van Oorschot, Wim. 2006. "Making the Difference in Social Europe: Deservingness Perceptions among Citizens of European Welfare States." Journal of European Social Policy 16(1): 23-42.

Petersen, Michael Bang. 2012. "Social Welfare as Small-Scale Help: Evolutionary Psychology and the Deservingness Heuristic." American Journal of Political Science 56(1): 1-16.

Rosset, Jan, and Jonas Pontusson. 2014. "The Impact of the Great Recession on Public Preferences for Redistribution in Western Europe."

Skitka, Linda J., and Philip E. Tetlock. 1993. "Providing Public Assistance: Cognitive and Motivational Processes Underlying Liberal and Conservative Policy Preferences." Journal of Personality and Social Psychology 65(6): 1205-23.

Soroka, Stuart, and Christopher Wlezien. 2014. "Economic Crisis and Support for Redistribution in the United Kingdom." Mass politics in tough times: Opinions, votes and protest in the great recession 105.

Will, J. A. 1993. "The Dimensions of Poverty: Public Perceptions of the Deserving Poor.” Social Science Research 22(3): 312-32. 


\section{Supplementary materials}

\section{Paired factorial vignette}

The exact text of the paired factorial vignette is found below. Each respondent was exposed to two pairs and used the slider allocating the funding for each.

In the following section, we would like you to read about people living in Canada during the current COVID-19 pandemic. Please read about each person's situation, then tell us how much government support, if any, you think they should receive per month during the pandemic.

$<$ Name $>$ is a $<$ citizenship $>$ currently living in a large Canadian city. $<$ Name $>$ is $<$ marital status $>$ and has $<$ children $>$. $<$ Name $>$ is $<$ employment status $>$. $<$ health status $>$. Prior to the COVID-19 pandemic, $<$ Name $>$ 's income was $<$ income $>$.

How much money should < name $>$ received from the government during the pandemic per month?

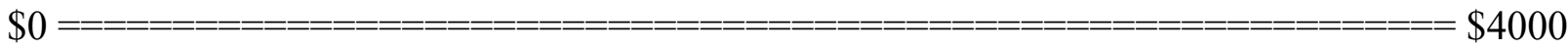

\begin{tabular}{|c|c|}
\hline Feature & Set \\
\hline $\begin{array}{l}\text { Name/Ethnicity/ } \\
\text { Gender }\end{array}$ & $\begin{array}{l}\text { - Matthew/Laurie Smith (White EN) OR Thomas/Emma Gagnon (White } \\
\text { - JR) } \\
\text { - } \text { Julia/John Wong (East Asian) } \\
\text { - } \quad \text { Robert/Linda Blackhawk (Indigenous) }\end{array}$ \\
\hline Health & $\begin{array}{l}\text { - They are in good health } \\
\text { - They have a pre-existing condition which makes them more at risk of } \\
\text { COVID-19 complications. }\end{array}$ \\
\hline Citizenship & $\begin{array}{l}\text { - } \quad \text { Canadian citizen } \\
\text { - } \quad \text { Canadian permanent resident } \\
\text { - } \text { Refugee }\end{array}$ \\
\hline Marital status & $\begin{array}{ll}\text { - } & \text { single } \\
\text { - } & \text { married }\end{array}$ \\
\hline Children & $\begin{array}{l}\text { - } \\
\text { - } \\
\text { - } \\
\text { - children under the age of } 5 \\
\text { children over the age of } 12\end{array}$ \\
\hline
\end{tabular}




\begin{tabular}{|l|l|}
\hline Feature & Set \\
\hline Employment & $\begin{array}{l}\text { - employed full-time and has not had any wage or hour reductions } \\
\text { employed full-time but their wages and hours have been reduced due to the } \\
\end{array}$ \\
& $\begin{array}{l}\text { - } \text { COVID-19 pandemic } \\
\text { - unemployed due to the COVID-19 pandemic }\end{array}$ \\
\hline Pre-crisis income & $\begin{array}{l}\text { - } \$ 30,000 \\
\end{array}$ \\
& - $\$ 60,000$ \\
& - $\$ 120,000$ \\
\end{tabular}

\section{Similarity variables}

Given multiple levels of the vignette features and respondent characteristics, the following design choices were made to identify social affinity or material self-interest considerations.

Table A1. Similarity Variable Construction

\begin{tabular}{|l|l|r|r|}
\hline Variable & Question wording and construction & Category & Yes \\
\hline \multirow{4}{*}{ Employment at risk } & & 19.8 \\
& Do you have a job at risk because of the & Maybe & 16.8 \\
& coronavirus? & No & 56.9 \\
& & Laid off & 6.5 \\
\hline Employment at risk - & 1 Yes OR laid off & & 27.0 \\
dichotomized & & 0 & 46.6 \\
& & 1 & 19.9 \\
Children & & 2 & 22.2 \\
& How many children do you have? & 3 & 7.3 \\
& & 4 & 2.4 \\
& & More than 4 & 1.7 \\
\hline Children - dichotomized & 1=1 OR 2 OR 3 OR 4 OR more than 4 & 54.1 \\
\hline \multirow{2}{*}{ Recent experience with } & 1=sore throat OR difficulty & & \\
illness - personally & breathing/shortness of breath OR fever OR & & 14.4 \\
& a severe dry cough OR loss of sense of sell & & \\
& OR a fever with hallucinations & & \\
\end{tabular}




\begin{tabular}{|l|l|r|r|}
\hline Variable & Question wording and construction & Category & $\%$ \\
\hline $\begin{array}{l}\text { Recent experience with } \\
\text { illness - household }\end{array}$ & $\begin{array}{l}\text { 1=sore throat OR difficulty } \\
\text { breathing/shortness of breath OR fever OR } \\
\text { a severe dry cough OR loss of sense of sell } \\
\text { OR a fever with hallucinations }\end{array}$ & 9.9 \\
\hline $\begin{array}{l}\text { Recent experience with } \\
\text { illness - combined }\end{array}$ & $1=$ personal OR household experience & & 17.2 \\
\hline & & $\$ 00,60,000$ & 40.3 \\
Income & Total household income & $\$ 90,001-200,000+$ & 39.4 \\
\hline Marital status & $1=$ married & & 46.3 \\
\hline Gender & $1=$ female & & 51.4 \\
\hline
\end{tabular}

Sub-group AMCE's

As per Leeper et al. (2020), evaluating subgroup preferences is best done using estimated differences in marginal means. Some audiences may prefer differences-in- AMCEs and so they are presented in Figure A1.

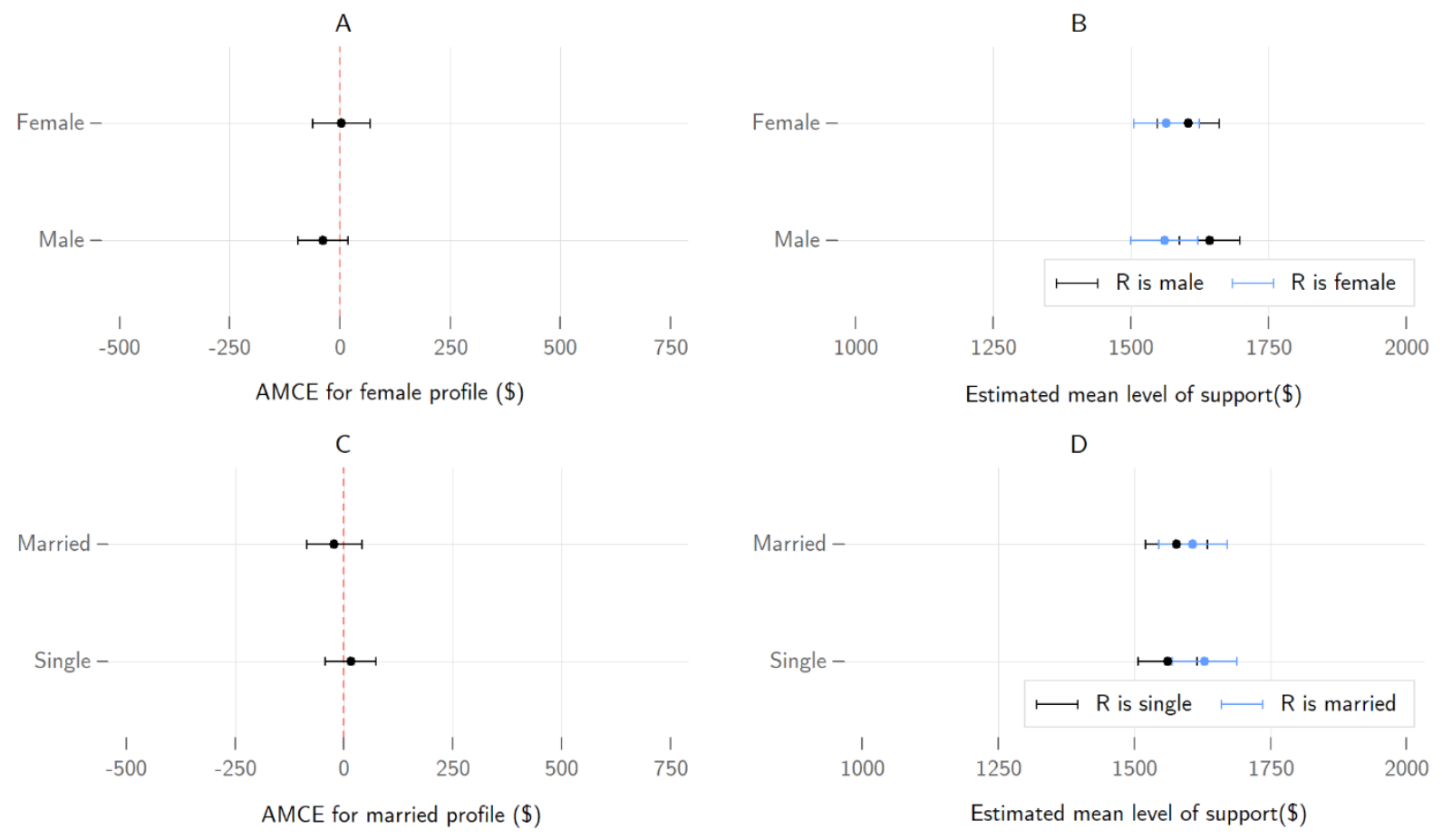

Figure A1. Sub-group AMCEs for gender (A), marital status (C); sub-group marginal means for gender (B), marital status (D). Note: 95\% confidence intervals. 